\title{
Risk factors associated with tobacco, alcohol and drug use among adolescents attending secondary school in three cities from Argentina
}

\author{
Paola Morello, M.D. ${ }^{a}$, Adriana Pérez, B.S. ${ }^{a}$, Lorena Peña, B.S. ${ }^{a}$, Sandra N. Braun, M.D. ${ }^{a}$, \\ Christy Kollath-Cattano, Inv. ${ }^{b}$, James F. Thrasher, Inv.$^{b}$, James Sargent, M.D. ${ }^{c}$ and Raúl Mejía, M.D. ${ }^{a}$
}

\begin{abstract}
Tobacco, alcohol and drug use starts at an early age. It isimportant toidentify risk factors associated with initiation. In 2014, a survey was conducted among students attending first year of secondary schools in Buenos Aires, Córdoba, and Tucumán. A total of 3172 students completed the survey ( $42 \%$ were girls); their mean age was 12.8 years old. Findings showed that $10 \%$ had smoked; $32 \%$ had consumed alcohol; $17 \%$ had a heavy drinking episode in the past month; and $8 \%$ had used at least one illegal drug once in their lifetime. A high sensation seeking index was associated with the use of tobacco (odds ratio [OR]: 4.25, 95\% confidence interval [CI]: 2.2-8.1), alcohol (OR: 5.56, 95\% CI: 3.73-8.31), and marijuana, coca paste or cocaine, (OR: $11.73,95 \%$ CI: 5.81-23.69). Having friends who smoke or drink was associated with tobacco (OR: $12.6,95 \%$ CI: 7.8-20.5) and alcohol use (OR: 5.17, 95\% CI: 4.15-6.40). Having permissive parents in terms of media use was associated with tobacco use (OR: 3.7, 95\% CI: 2.1-6.5), and perceiving a low parental support and control (OR: 3.02, 95\% CI: 1.40-6.52) was associated with marijuana, coca paste and cocaine use.
\end{abstract}

Key words: tobacco, alcohol, illegal drugs, adolescent, Argentina.

http:/ /dx.doi.org/10.5546/aap.2017.eng.155

To cite: Morello P, Pérez A, Peña L, et al. Risk factors associated with tobacco, alcohol and drug use among adolescents attending secondary school in three cities from Argentina. Arch Argent Pediatr 2017;115(2):155-159.

a. Center for State and Society Studies (Centro de Estudios de Estado y Sociedad, CEDES). Autonomous City of Buenos Aires, Argentina.

b. Arnold School of Public Health, University of South Carolina, United States of America.

c. Department of Pediatrics, Geisel School of Medicine of Dartmouth College, United States.

E-mail address: Paola Morello, M.D.: paolamorello@hotmail.com

Funding: This study was funded by the "Tobacco and movies in Latin America" grant awarded by the Fogarty International Center at NIH (grant R01 TW009274-01).

Conflict of interest: None.

Received: 3-14-2016

Accepted: 8-22-2016

\section{INTRODUCTION}

Tobacco, alcohol and drug use is highly prevalent among adolescents. ${ }^{1-4}$ Having updated information on tobacco, alcohol and drug use during early adolescence and associated social and personal factors may help to develop public policies aimed at preventing their use in Argentina.

The purpose of this research was to determine factors associated with the initial use of tobacco, alcohol, marijuana, and coca paste or cocaine among young adolescents from three Argentine cities.

\section{POPULATION AND METHODS}

A survey was administered among students attending the first year of secondary school as part of a study conducted in Mexico and Argentina to assess youth exposure to tobacco and alcohol in motion pictures and the relationship to tobacco, alcohol and drug use. ${ }^{5-7}$ Between May and June 2014, students from 33 public and private schools from the city of Buenos Aires, city of Córdoba, and San Miguel de Tucumán completed a selfadministered anonymous survey during class.

The survey included questions on sociodemographic and personal aspects, school performance, tobacco use among family members and friends, parenting styles, access to and restrictions on media (computer, $\mathrm{TV}$, etc.), use of tobacco, alcohol, marijuana, and coca paste or cocaine. Predictive outcome measures included sex, age, maximum level of education attained by either parent $(\leq 7,8-12,>12$ years of formal education), type of school (public or private), repeat student, household members who smoke, and tobacco and alcohol use among friends. In addition, a "sensation seeking" index was included, reflecting participants' desire to experience new things, and a "parenting style" index regarding both parents to assess the perceptions adolescents have about parental control and emotional support. A "media access" index was created based on whether participants had their own TV, DVD or Blu-ray player, tablet, computer, video game console, or mobile phone, 
together with a "parental rules on media use" index. These indices were used for the first time in Argentina. Cronbach's alpha was estimated to measure their reliability, which was $0.79,0.74$, 0.61 , and 0.62 , respectively. A detailed description of the methodology and part of results have already been published..$^{5-7}$

A multilevel logistic regression was done for analysis, with an estimation of odds ratios (ORs) and the corresponding 95\% confidence intervals (CIs) as adjusted for each substance use. Data were analyzed using the Stata V.13.0 software (Stata Corp, College Station, TX, USA).

\section{RESULTS}

Out of the 3826 eligible students, 3172 $(83 \%)$ completed the survey. Table 1 shows the sociodemographic and personal characteristics of participants by city of residence. Participants' mean age was 12.8 years old. In the 30 days prior to taking the survey, $10 \%$ of students had smoked, 32\% had consumed alcohol, 17\% had a heavy drinking episode, and $8 \%$ had used both tobacco and alcohol. In addition, $8 \%$ referred having used at least one illegal drug once in their lifetime. Table 2 describes tobacco, alcohol and drug use (marijuana, cocaine or coca paste) by sex and city of residence. Having friends who smoke (OR: 12.6, 95\% CI: 7.8-20.5), a high sensation seeking index (OR: 4.25, 95\% CI: 2.2-8.1), and having permissive parents in terms of media use (OR: 3.7, 95\% CI: 2.1-6.5) were the most relevant outcomes related to tobacco use. A high sensation seeking index (OR: 5.56, 95\% CI: 3.73-8.31), and having friends who smoke (OR: 5.17, 95\% CI: 4.156.40) were the most relevant outcomes associated with alcohol use. A high sensation seeking index (OR: 11.73, 95\% CI: 5.81-23.69), and a low parental control and support (OR: 3.02, 95\% CI: 1.406.52) were the most relevant outcomes related to marijuana, and coca paste or cocaine use. Figure 1 shows multivariate analysis results, with adjusted ORs ordered by size of their effect on the use of each substance.

TABLE 1. Characteristics of participants by city

\begin{tabular}{|c|c|c|c|c|}
\hline & $\begin{array}{c}\text { Buenos Aires } n=1664 \\
\text { n (\%) }\end{array}$ & $\begin{array}{c}\text { Córdoba } n=983 \\
n(\%)\end{array}$ & $\begin{array}{c}\text { Tucumán n= } 525 \\
n(\%)\end{array}$ & $\begin{array}{c}\text { Total } \mathbf{n}=3172 \\
\mathrm{n}(\%)\end{array}$ \\
\hline \multicolumn{5}{|l|}{ Sociodemographic characteristics } \\
\hline Girl & $627(37.9)$ & $396(40.6)$ & $312(59.9)$ & $1335(42.4)$ \\
\hline \multicolumn{5}{|l|}{ Age (years old) } \\
\hline$\leq 12$ & $123(7.4)$ & $739(75.3)$ & $479(91.2)$ & $1341(42.3)$ \\
\hline $13-14$ & $1353(81.4)$ & $229(23.3)$ & $44(8.4)$ & $1626(51.3)$ \\
\hline$\geq 15$ & $186(11.2)$ & $14(1.4)$ & $2(0.4)$ & $202(6.4)$ \\
\hline \multicolumn{5}{|l|}{ Maximum parental level of education } \\
\hline Complete or incomplete primary school & $135(9.0)$ & $64(7.6)$ & $15(3.3)$ & $214(7.7)$ \\
\hline Complete or incomplete secondary school & $699(46.6)$ & $447(53.3)$ & $143(31.2)$ & $1289(46.1)$ \\
\hline Incomplete tertiary education or higher & $665(44.4)$ & $327(39.0)$ & $300(65.5)$ & $1292(46.2)$ \\
\hline Employed & $137(8.3)$ & $86(8.9)$ & $28(5.4)$ & $251(8.0)$ \\
\hline Attending a public school & $1551(93.2)$ & $515(52.4)$ & $93(17.7)$ & $2159(68.1)$ \\
\hline \multicolumn{5}{|l|}{ Social influences } \\
\hline Any friend who smokes & $800(48.3)$ & $400(41.0)$ & $150(28.6)$ & $1350(42.8)$ \\
\hline Any household member who smokes & $842(51.0)$ & $626(64.3)$ & $283(54.1)$ & $1751(55.6)$ \\
\hline Any friend who drinks & $986(59.7)$ & $449(46.0)$ & $229(43.7)$ & $1664(52.8)$ \\
\hline \multicolumn{5}{|l|}{ Personal characteristics } \\
\hline Repeat student & $517(31.3)$ & $211(21.6)$ & $39(7.5)$ & $767(24.4)$ \\
\hline Sensation seeking index $(0-1)^{*}$ & $0.56(0.27)$ & $0.54(0.26)$ & $0.55(0.26)$ & $0.55(0.27)$ \\
\hline Parenting style index $(0-1)^{*}$ & $0.72(0.19)$ & $0.77(0.19)$ & $0.78(0.18)$ & $0.75(0.19)$ \\
\hline Parental rules on media use index $(0-1)^{*}$ & $0.30(0.31)$ & $0.45(0.32)$ & $0.52(0.32)$ & $0.38(0.33)$ \\
\hline Media access index $(0-1)^{*}$ & $0.71(0.22)$ & $0.61(0.25)$ & $0.67(0.23)$ & $0.67(0.24)$ \\
\hline Internet access in the bedroom & $1442(88.0)$ & $691(72.0)$ & $431(83.9)$ & $2564(82.4)$ \\
\hline Mobile phone1399 & $(85.1)$ & $791(81.5)$ & $471(90.6)$ & $2661(84.9)$ \\
\hline TV in the bedroom & $1439(87.5)$ & $810(83.3)$ & $456(87.5)$ & $2705(86.2)$ \\
\hline TV in the bedroom & $952(58.2)$ & $458(47.5)$ & $262(50.6)$ & $1672(53.6)$ \\
\hline Computer (not shared) & $1324(80.9)$ & $555(57.5)$ & $331(63.9)$ & $2210(70.8)$ \\
\hline Tablet & $548(33.5)$ & $267(27.8)$ & $201(38.7)$ & $1016(32.6)$ \\
\hline
\end{tabular}

* Mean (standard deviation). 


\section{DISCUSSION}

In this population of young adolescents, the prevalence of tobacco, alcohol and drug use was lower than that reported in other recent national surveys, and was dissimilar across the different surveyed cities. ${ }^{2,3,4}$ Risk factors that showed a stronger association with tobacco and alcohol use included having close friends who smoke or drink and a high sensation seeking index. Also, a high sensation seeking index and a low parental support and control index were the most important risk factors for illegal drug use.

The difference in the prevalence of use compared to national surveys may be explained by the younger age of the students included in this study, especially in Tucumán, where 90\% of students were younger than 12 years old. However, $27 \%$ of survey respondents were susceptible to smoking in the following year, so tobacco use would likely increase as this population gets older. ${ }^{8}$ In relation to alcohol use, $24 \%$ of participants considered they were susceptible to drinking in the following year. The difference observed in relation to drug use may be explained not only by participants' younger age, but also by the fact that the national survey had included energy drinks, solvents, psychotropic drugs, and other components included in the definition of "other drugs." 4 The difference in terms of prevalence among the three cities may be accounted for by the different sample structures, as observed in Table 1.
In many countries, youth whose friends smoke have a higher risk of taking up and continuing smoking than those whose friends do not smoke. ${ }^{9}$ Our study also indicates that having friends who smoke is significantly associated with tobacco use. Additionally, having friends who drink was also significantly associated with alcohol use. Adolescents who tend to seek new sensations, either because of their personality or because they are exposed to motion pictures or video games that encourage such sensations, have a higher risk for substance use. ${ }^{10,11}$ The perception adolescents have about the balance between parental control (rules) and emotional support is also relevant. The presence of rules is a protective factor against both smoking initiation and heavy episodic drinking. ${ }^{12,13}$ In Anglo-Saxon countries, restrictions imposed by parents in relation to access to motion pictures and video games that are prohibited for minors reduce substance use among their children. ${ }^{14}$ The importance of parental control in terms of media access in this population has been published already. ${ }^{5}$

This study has certain limitations: the sample was not selected in a probabilistic fashion and included only adolescents who attended school. The survey included indices originally developed in English-speaking countries, and did not ask about alcohol and drug use among family members and friends. However, as per the National Population, Households and Housing Census, conducted in 2010 and published by

TABle 2. Prevalence of tobacco, alcohol and illegal drug use by city

\begin{tabular}{|c|c|c|c|c|c|c|c|c|c|c|c|c|c|c|}
\hline & \multicolumn{4}{|c|}{ Buenos Aires } & \multicolumn{4}{|c|}{ Córdoba } & \multicolumn{4}{|c|}{ Tucumán } & \multicolumn{2}{|c|}{ Total } \\
\hline & \multicolumn{2}{|c|}{ Girls } & \multicolumn{2}{|c|}{ Boys } & \multicolumn{2}{|c|}{ Girls } & \multicolumn{2}{|c|}{ Boys } & \multicolumn{2}{|c|}{ Girls } & \multicolumn{2}{|c|}{ Boys } & \multirow[b]{2}{*}{$\mathbf{n}$} & \multirow[b]{2}{*}{$\%$} \\
\hline & n & $\%$ & $\mathbf{n}$ & $\%$ & $\mathbf{n}$ & $\%$ & $\mathbf{n}$ & $\%$ & $\mathbf{n}$ & $\%$ & $\mathbf{n}$ & $\%$ & & \\
\hline \multicolumn{15}{|l|}{ Tobacco } \\
\hline Never smoked & 431 & $(68.7)$ & 792 & $(77.0)$ & 329 & $(83.3)$ & 475 & $(82.0)$ & 271 & $(86.9)$ & 188 & $(90.0)$ & 2486 & $(78.9)$ \\
\hline Susceptible to smoking* & 138 & $(32.2)$ & 211 & $(26.8)$ & 97 & (29.5) & 121 & (25.5) & 59 & (21.8) & 30 & $(16.0)$ & 656 & $(26.5)$ \\
\hline Present smoker & 99 & $(15.8)$ & 113 & $(11.0)$ & 34 & $(8.6)$ & 48 & $(8.3)$ & 10 & $(3.2)$ & 10 & $(4.8)$ & 314 & $(10.0)$ \\
\hline \multicolumn{15}{|l|}{ Alcohol } \\
\hline Never drank & 208 & $(33.2)$ & 334 & $(32.5)$ & 171 & $(43.2)$ & 211 & $(36.4)$ & 128 & (41) & 80 & (38.3) & 1132 & $(35.9)$ \\
\hline to drinking* & 46 & $(22.2)$ & 99 & $(29.8)$ & 44 & (25.7) & 35 & (16.6) & 25 & $(19.7)$ & 16 & $(20)$ & 265 & $(23.5)$ \\
\hline Present alcohol user & 239 & $(38.1)$ & 345 & (33.5) & 106 & $(26.8)$ & 189 & (32.6) & 75 & $(24)$ & 63 & $(30.1)$ & 1017 & $(32.3)$ \\
\hline Heavy episodic drinking & 170 & $(27.2)$ & 222 & $(21.7)$ & 49 & (12.4) & 61 & $(10.6)$ & 25 & $(8.1)$ & 13 & $(6.2)$ & 540 & $(17.2)$ \\
\hline \multicolumn{15}{|l|}{ Illegal drugs } \\
\hline Has tried marijuana & 63 & $(10.1)$ & 130 & $(12.7)$ & 12 & (3.0) & 34 & $(5.9)$ & 2 & $(0.6)$ & 0 & $(0)$ & 241 & (7.7) \\
\hline Has tried cocaine or coca paste & 12 & $(1.9)$ & 28 & $(2.7)$ & 5 & $(1.3)$ & 12 & $(2.1)$ & 1 & $(0.3)$ & 2 & $(1.0)$ & 60 & (1.9) \\
\hline $\begin{array}{l}\text { Has tried marijuana, cocaine, } \\
\text { or coca paste }\end{array}$ & 64 & (10.2) & 136 & $(13.2)$ & 13 & (3.3) & 40 & (6.9) & 3 & $(1.0)$ & 2 & $(1.0)$ & 258 & (8.2) \\
\hline
\end{tabular}

* Estimated among non-smokers and non-drinkers, respectively. 
the National Statistics and Censuses Institute of Argentina (Instituto Nacional de Estadística $y$ Censos, INDEC) in 2012, the three provinces included in the study account for $37 \%$ of the national population; and both public and private schools were selected to account for different socioeconomic levels.

In spite of limitations, the results of this survey provide information on socioeconomic, cultural, and personal outcome measures that may serve as predictors of substance use among young adolescents in Argentina. In addition, risk factors included in the study are innovative in our setting, such as "sensation seeking," "parenting styles," "media access," which have not been included in any published study in Argentina.

The results of this study show associations that should be analyzed in further studies in order to explain the temporal relationship between the identified predictive factors and substance use initiation and continuation among young adolescents. Given the differences observed in terms of use among the three cities, further studies to analyze the reasons for such differences are deemed necessary.

Having these results in mind, pediatricians should take advantage of office visits to screen for adolescents with a high sensation seeking index or who have friends who smoke. In addition, pediatricians may help parents with prevention

FIGURE 1: ORs as adjusted for tobacco, alcohol and drug use. Each graph shows the adjusted ORs and 95\% confidence intervals, ordered by size, so that risk factors can be compared
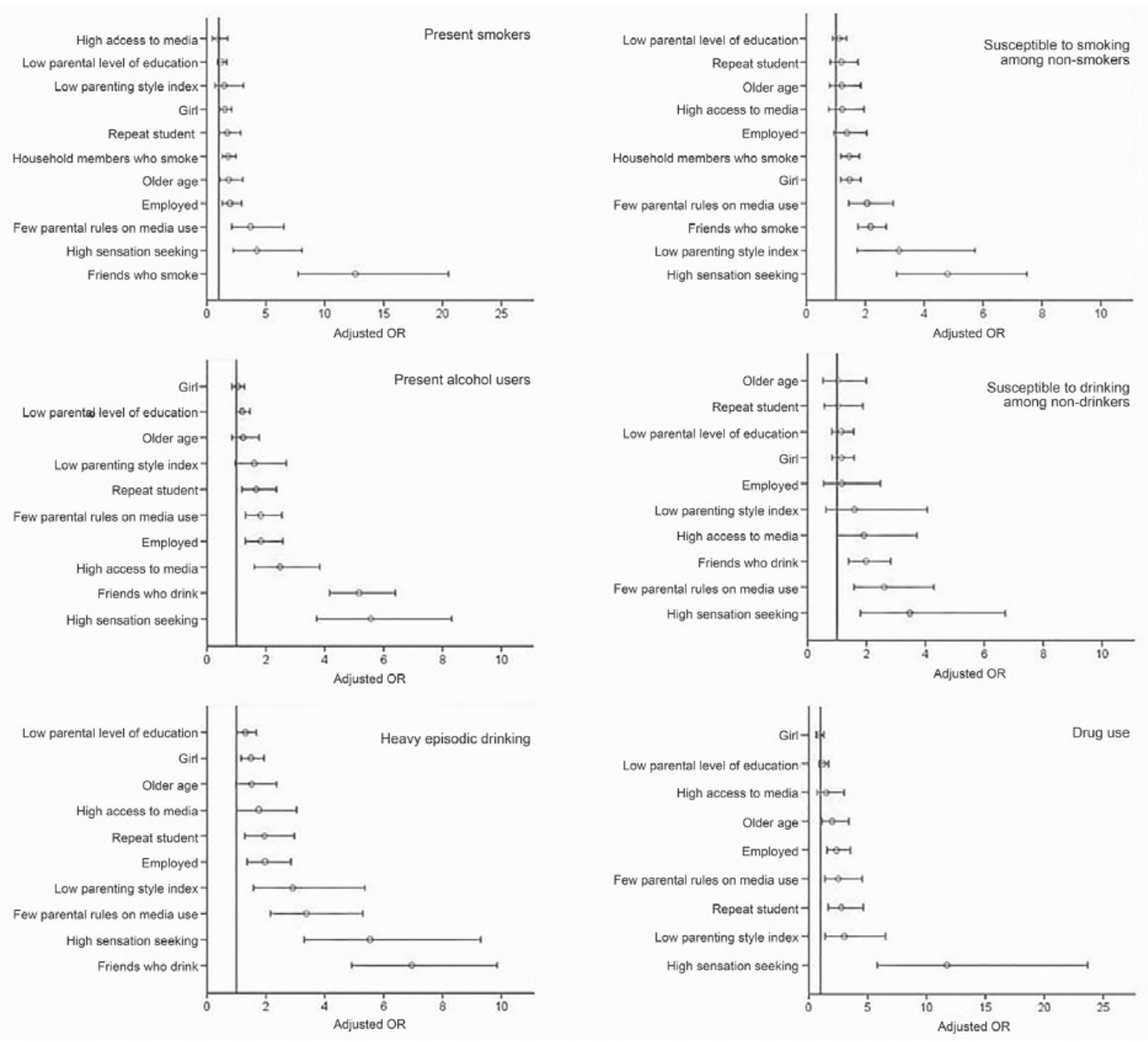
by giving them advice on effective strategies to monitor media use by their children.

\section{CONCLUSION}

Sensation seeking, tobacco and alcohol use by close friends, and a low parental control were associated with the initiation of tobacco, alcohol and marijuana or coca paste use in this population of young adolescents.

\section{Acknowledgments}

We would like to thank the investigators of the National Institute of Public Health of Mexico: Edna Arrillo Santillán, M.D., Inti Barrientos, M.D., and Rosaura Pérez Hernández, B.S., for their help designing the survey and their comments regarding the manuscript. We would also like to thank Silvia Hernández, B.S., from the Ministry of Education of the City of Buenos Aires, Carlos Dalmiro Paz, M.D., and Liliana Avaca, from the Ministry of Education of Córdoba, and Cristina Orellana, M.D., from the Provincial Tobacco Control Program of Tucumán, for their help administering the surveys.

\section{REFERENCES}

1. Johnston LD, O'Malley PM, Bachman JG, Schulenberg JE. Monitoring the Future national survey results on drug use, 1975-2012: Secondary school students. Ann Arbor: Institute for Social Research, The University of Michigan, 2013. [Accessed on: July $\left.10^{\text {th }}, 2015\right]$. Available at: http:// www.monitoringthefuture.org/pubs/monographs/mtfvol1_2012.pdf.

2. Argentina. Ministerio de Salud de la Nación. Encuesta Mundial de Tabaquismo en jóvenes (EMTJ). Argentina 2012. [Accessed on: July 10 $\left.10^{\text {th }}, 2015\right]$. Available at: http:// www.msal.gob.ar/ent/images/stories/vigilancia/pdf/201403_informe-gyts-jovenes.pdf.

3. Argentina. Ministerio de Salud de la Nación. Segunda Encuesta Mundial de Salud Escolar (EMSE). Argentina: 2012. [Accessed on: July 10 $\left.10^{\text {th }}, 2015\right]$. Available at: http:// www.msal.gob.ar/ent/images/stories/vigilancia/pdf/201409_informe-EMSE-2012.pdf.
4. SEDRONAR. Sexto Estudio Nacional sobre consumo de sustancia psicoactivas en Estudiantes de Enseñanza Media 2014. Boletín N. ${ }^{\circ} 1$ Patrones y magnitud del consumo: diagnóstico a nivel país. Buenos Aires: Secretaría de Programación para la Prevención de la Drogadicción y la Lucha contra el Narcotráfico, 2014. [Accessed on: 24 de agosto de 2016]. Available at: http:/ / scripts.minplan.gob. ar/octopus / archivos. php?file $=4121$.

5. Mejia R, Pérez A, Peña L, MorilloP, etal. Parental Restriction of Mature-rated Media and Its Association With Substance Use Among Argentinean Adolescents. Acad Pediatr 2016;16(3):282-9.

6. Mejia R, Pérez A, Abad-Vivero E, Kollath-Cattano C, et al. Exposure to Alcohol Use in Motion Pictures and Teen Drinking in Latin America. Alcohol Clin Exp Res 2016;40(3):631-7.

7. Braun S, Kollath-Cattano C, Barrientos I, Mejía R, et al. Assessing tobacco marketing receptivity among youth: integrating point of sale marketing, cigarette package branding and branded merchandise. Tob Control 2015 [Epub ahead of print].

8. Pierce JP, Choi WS, Gilpin E A, Farkas AJ, et al. Validation of susceptibility as a predictor of which adolescents take up smoking in the United States. Health Psychol 1996;15(5):35561.

9. U.S. Department of Health and Human Services. Preventing Tobacco Use Among Youth and Young Adults: A Report of the Surgeon General. Atlanta, GA: Department of Health and Human Services, Centers for Disease Control and Prevention, NationalCenter for Chronic Disease Prevention and Health Promotion, Office on Smoking and Health, 2012. [Accessed on: August $\left.24^{\text {th }}, 2016\right]$. Available at: http:// www.surgeongeneral.gov/library/reports/preventingyouth-tobacco-use / full-report.pdf.

10. Sargent JD, Tanski S, Stoolmiller M, Hanewinkel R. Using sensation seeking to target adolescents for substance use interventions. Addiction 2010;105(3):506-14.

11. Comeau N,StewartSH,Loba P. The relations of trait anxiety, anxiety sensitivity, and sensation seeking to adolescents' motivations for alcohol, cigarette, and marijuana use. Addict Behav 2001;26(6):803-25.

12. Stephenson MT, Helme DW. Authoritative parenting and sensation seeking as predictors of adolescent cigarette and marijuana use. J Drug Educ 2006;36(3):247-70.

13. Jackson C, Henriksen L, Dickinson D. Alcohol-specific socialization, parenting behaviors and alcohol use by children. J Stud Alcohol 1999;60(3):362-7.

14. DaltonMA, Adachi-Mejia AM, LongacreMR, Titus-Ernstoff LT, et al. Parental rules and monitoring of children's movie viewing associated with children's risk for smoking and drinking. Pediatrics 2006;118(5):1932-42. 